\title{
OBESITY IN A CHILD
}

\author{
BY \\ DUNCAN MACAULAY \\ From the City Hospital, Derby
}

(Received for Publication December 11, 1950)

The following case is reported for two reasons. In the first place, the patient exhibits in an unusually distinct manner the factors which appear to underlie most instances of obesity in childhood, and secondly it was possible to detain a cooperative and intelligent patient in hospital for long enough to conduct a simple experiment which does not seem to have been recorded previously.

\section{Case Report}

The patient was a girl of 11 years who was referred because of obesity. She was the last of four children, of whom one had died in infancy. The dates of the births of the children were: 1923, 1926, 1929 (this child died at the age of one month), and 1939. The mother's age at the time of the girl's birth was 41 years. The gap of 10 years between the third and fourth pregnancies, the fact that the third child had died in infancy, and the patient's arrival at the end of her mother's reproductive life, all contributed to make her an object of special regard from the day of her birth. In the mother's words: 'she always had special care taken of her '.

Her sister was plump, but not excessively stout. The brother was said to be thin. The mother stated that she herself had been very stout until the age of 14 when she had lost much of her excess weight. At the time of interview she was certainly overweight but not grossly obese. The maternal grandmother was said to have been stout, but the male members of the family on both sides were reported to be slim.

The child weighed $7 \mathrm{lb}$. at birth, and was said then to have been normal. Breast-feeding was continued for nearly two years, and solids were not successfully introduced until the age of 18 months. The mother stated that she had made repeated attempts to discontinue breast-feeding after the first year, but the child insisted on having the breast even when she was taking adequate meals.

No record of weights was kept, but the mother reported that from about the age of 3 years the child began to gain weight rapidly and that the excessive gain in weight had continued since then. Her mental development was apparently normal. She went to school at the usual time and had maintained average progress.
Physically she had appeared normal apart from the obesity and a deformity of the right foot. She had had the usual infectious fevers without sequelae and an appendicectomy in December, 1949.

The whole family were said to be 'good eaters'. The mother, on direct questioning, admitted that the girl ate as much as the adult members of the family. She would eat large amounts of any food offered, but had a special predilection for starchy foods. She usually ate four slices of bread at a sitting, and would take six or seven large potatoes as a helping; fried chipped potatoes were her special weakness. In the family these eating habits were regarded as normal. Her fluid intake was not excessive.

The deformity of the foot which prevented her playing games has already been noted. She was said to avoid other children, and on return from school she remained indoors engaged in a variety of sedentary occupations such as reading, knitting, etc.

When she was examined on admission to hospital she was seen to be very obese (Fig. 1 A). She weighed $132 \mathrm{lb}$. and was 58 in. tall. That is, she was approximately $70 \%$ overweight, but within the normal limits of height for her age. The fat showed no unusual distribution. There was no pitting oedema of the legs. The skin was dull, but there was no hirsutism or abnormal coloration. Breast development was apparent, but the large deposits of fat made the true size of the breasts difficult to decide. There was no pubic hair, and she had not menstruated. Hallux valgus of the right great toe was present. Otherwise examination revealed no abnormality. Her blood-pressure was 105/70 and the optic discs were normal.

Mentally she was a quiet, shy, withdrawn child who spoke little and in a low voice. She appeared to be mildly depressed and spontaneous movements were few. Her intelligence was better than average. (No tests were performed, but the school-teacher who visited the ward considered that her performance in set tasks was above average.) The general impression she gave was of a rather pathetic, discouraged child, conscious of her ungainly appearance, who tended to isolate herself.

The following investigations gave essentially normal results: urine analysis, full blood count, examination of the faeces, glucose tolerance test, blood cholesterol and 
serum protein levels, radiographs of the ulnar epiphyses to determine bone age and of the skull for size of the pituitary fossa.

She was assessed as a case of simple obesity without endocrine or other abnormalities.

Five days after admission to hospital, she was started on a diet of 1,150 calories, containing $100 \mathrm{~g}$. of carbohydrate, $70 \mathrm{~g}$. of protein, and $50 \mathrm{~g}$. of fat. Salt was withheld during cooking and at table. She continued on this diet for the duration of her stay in hospital. She was a most cooperative patient whose conduct was exemplary and whose anxiety to lose weight became very manifest.

On the twentieth day in hospital an operation to correct the deformity of the toe was performed and just before and after this she was confined to bed for 15 days. Otherwise she was up for most of the day and became a useful helper in the ward.

Her intake of fluids and her urinary output were measured from the date of admission. In the first period no restrictions were imposed, and she was allowed to drink when she liked and as much as she wished. The purpose was to determine her usual intake of fluids, and her rate of loss of weight on this intake on the basal diet. This period lasted for 44 days, but the fluid measurements were discontinued for the period during which she was confined to bed. Thus figures are available for 29 days. During this period her average daily intake was 29 fluid oz. (maximum, 45 oz., minimum, 20 oz.).

At the end of this period she was asked to drink as much water as she could without discomfort; this forced intake was continued for eight days. Thereafter she was requested to restrict her intake of fluids to the minimum she could manage without discomfort; this was continued for six days. At the end of this time she was again asked to drink to capacity. These alternating periods of restriction and excess were continued for a total of 41 days. The variability of intake was very marked. The average intake in the periods when she was drinking as much as she could was 92 fluid $\mathrm{oz}$. (maximum, 127 oz., minimum, 41 oz.), and during the periods of restriction only $15 \mathrm{oz}$. (maximum, $21 \mathrm{oz}$., minimum, 10 oz.).

She was weighed daily in the same clothes, at the same time, and after emptying her bladder. The weight curve during the preliminary period of observation showed the usual fluctuations encountered in obese persons on a reducing diet (Newburgh, 1944; Evans, 1947), but over the whole period there was a loss of $10 \mathrm{lb} .8 \mathrm{oz}$., i.e. an average daily loss of just under $4 \mathrm{oz}$.

The results during the controlled periods are shown graphically in Fig. 2. Urinary outputs are shown at the top, the weight curve in the middle and the fluid intakes at the bottom. The + signs indicate days when the urinary output exceeded the fluid intake. The continuous thin line under the weight curve is the 'expected weight loss,' i.e. the weight loss which would have been anticipated on the basis of the rate of loss during the period of uncontrolled fluid intake. The vertical lines indicate the points of change from excessive intake to restricted intake and vice versa.

The effect of the greatly increased fluid intake is apparent in the tendency of the weight curve to flatten out or even to rise during the first five or six days of each period. This is associated with a marked discrepancy between urinary output and fluid intake, most noticeable in the third period. On the sixth or seventh day, however, the weight showed a tendency to drop, and the urinary output increased. Taking the three periods together there was, during the first five days of excessive intake, an average gain in weight of $1 \frac{1}{2} \mathrm{oz}$. per day; on the sixth and seventh days there was contrarily an average loss of $4 \mathrm{oz}$. per day.

When the intake was restricted there was first a dramatic reduction in urinary output. This was followed by a diuresis in spite of the continued restriction, i.e. by an excess of urinary volume over daily intake. The weight loss was not constant or regular, but in the first three days the average loss was $10 \mathrm{oz}$., and in the second three days $5 \mathrm{oz}$. per day.

At the end of the experiment the child weighed $112 \mathrm{lb}$. $4 \mathrm{oz}$. She was much more cheerful and sociable (Fig. 1B).

After discharge she has been seen several times as an out-patient and has continued to lose weight, though at a slower rate, on a rather less restricted diet. The change in her attitude is marked. Now, on returning from school she hurries out to be with her friends; she is most particular about her diet and is interested in her appearance in an active healthy fashion. 


\section{Comment}

The factors concerned in the genesis of this girl's obesity appear to be the following: (1) a familial tendency to plumpness of the females in the family; (2) restricted physical activity, due in part to the deformity of the foot, but even more to a feeling of insecurity with other children; and (3) faulty eating habits, primarily due to overzealous parental care.

The three basic factors may be termed genetic, physical, and psychological. Of these the last appears to be the most important, since it accentuates the rather small effects of the other two and leads directly to the major cause of the obesity, viz. overeating.

The factors which, it seems safe to assume, are not concerned are an endocrine upset, of which there is no evidence of any sort, and water retention.

It is clear that during the early part of the periods of forced intake there was a certain amount of water retention. However, as the decrease in weight at the end of these periods, associated with a marked increase in urinary volume, show, this was a self-limiting process.

The capacity of adipose tissue to retain water is well known. It is a phenomenon which in some countries has been of economic importance, since the ability of the camel to go for prolonged periods without water is dependent on its possession of a portable reservoir in the form of its hump. Grafe (1933) reports that the fluid content of human fat has been found by several investigators to vary from $5 \%$ to $71 \%$. He states that 'fatty tissues absorb water like a sponge, without circulatory disturbances and with no evidence of oedema.' The curious phenomenon by which this retained water is held in the tissue with great tenacity during periods of undernutrition has been repeatedly commented on (Grafe, 1933; Newburgh, 1944; Evans, 1947; Greene, 1948). Wiley and Newburgh (1931) have shown that this occurs in normal individuals during periods of starvation. Grafe says that ' every undernutrition leads to retention of fluid, and Newburgh concluded from his experimental data that 'excessive retention of water is seen to be merely a by-product of undernutrition. It in no way indicates that the metabolism of obese persons is abnormal.'

In the present case it was found impossible to achieve a persistent gain in weight on intakes of water which were on the average more than three times the normal consumption, and such water as was stored on these excessive intakes was very readily excreted during the periods of restriction. It seems improbable that on her usual intake this child stored water to any appreciable extent.

This patient illustrates very clearly the importance of Bruch's (1940) demonstration that in a large number of cases of childhood obesity, food has a special significance in the parent-child relationship, and that the excessive consumption often represents 
a search by the child for comfort which it does not find in other ways. The most striking feature of the present case was the marked change in the girl's attitude to herself and her environment. This was due to three things: the indubitable demonstration that she could lose weight and remain well; the close contact with other children in the ward; and the constant interest in her progress displayed by the medical and nursing staff. She ceased to be the timid child afraid of giving up the breast and became a real person, able to control her environment with reasonable success and assurance.

\section{Summary}

The case of a girl with marked obesity is reported in which an attempt to demonstrate water-retention was made during a period in hospital. The results indicate that on very large fluid intakes a small amount of water-retention occurred, but that this stored water was easily removed by restriction of fluids. It seems unlikely that in this case water storage played any important part in determining the child's bulk. The most important factors, both in aetiology and in treatment, were psychological.

Dr. D. V. Hubble who was in charge of the case gave permission for the experiment to be performed and for publication of this report. Sister B. Wilson supervised the fluid measurements. To both I wish to express my thanks.

\section{REFERENCES}

Bruch, H. (1940). Amer. J. Dis. Child., 59, 739.

Evans, F. A. (1947). In 'Diseases of Metabolism,' edited Duncan, G. G. 2nd ed. Philadelphia.

Grafe, E. (1933). "Metabolic Diseases and their Treatment '(English Translation). Philadelphia.

Greene, R. (1948). 'The Practice of Endocrinology.' London.

Newburgh, L. H. (1944). Physiol. Rev., 24, 18.

Wiley, F. H., and Newburgh, L. H. (1931). J. clin. Invest., 10, 723 